\title{
APLIKASI PERENCANA KEUANGAN PADA PLATFORM BERBASIS SMARTPHONE MULTIPLATFORM DENGAN FRAMEWORK PHONEGAP
}

\author{
Nurul Faizah Rozy ${ }^{1}$, Sholahuddin Alisyahbana ${ }^{2}$ \\ Program Studi Teknik Informatika Fakultas Sains dan Teknologi \\ UIN Syarif Hidayatullah Jakarta \\ J1. Ir. H. Juanda No. 95 Ciputat 15412 \\ Telp. (+62-21) 7493606, 7493547 Fax: (+62-21)7493315
}

\begin{abstract}
ABSTRAK
Pengelolaan keuangan diperlukan guna mengatur keuangan secara baik. Sebelas alasan mengapa perencanaan keuangan perlu dilakukan , yaitu karena melalui proses perencanaan keuangan kita lebih bisa untuk: Melindungi diri dan keluarga dari dampak keuangan risiko kecelakaan, penyakit, kematian, dan tuntutan hukum; Mengurangi utang pribadi/keluarga; Membiayai keuangan bila hidup ini tidak lagi dalam rentang usia produktif - terkait dengan tingkat yang lebih tinggi harapan hidup rata rata di suatu di negara; Membayar biaya-biaya untuk membesarkan anak; Memberikan alokasi pendidikan bagi anak-anak ke ke perguruan tinggi; Membiayai pernikahan anak perempuan kita; Untuk membeli kendaraan; Untuk membeli rumah; Mampu menentukan gaya hidup yang kita inginkan saat pensiun; Membayar biaya biaya perawatan jangka panjang; dan Mewariskan kesejahteraan ke generasi selanjutnya (anak, cucu, dan lain-lain). Dalam perkembangan teknologi saat ini penggunaan smartphone berkembang pesat sehingga dibutuhkan aplikasi perencana keuangan berbasis smartphone. Untuk itu, dibangunlah sebuah aplikasi perencana keuangan berbasis smartphone dengan menggunakan framework Phonegap sehingga aplikasi yang dihasilkan dapat dijalankan pada smartphone dengan berbagai platform. Metode pengembangan sistem ini menggunakan Rapid Application Development (RAD) dengan tiga fase yaitu, perencanaan kebutuhan, fase workshop design, dan fase implementasi. Phonegap adalah sebuah framework open source untuk membangun aplikasi di perangkat mobile. Phonegap menggunakan metode cross-platform Application Development sehingga pengembang hanya membuat sekali basis kode dan Phonegap yang mentransformasikan hasil keluaran aplikasi untuk beberapa smartphone seperti Android, Blackberry OS, dan Windows Phone. Dengan menggunakan framework phonegap, aplikasi dapat dibangun dengan menggunakan bahasa pemrograman HTML5, CSS, Javascript, dan SQLite sebagai database.
\end{abstract}

Kata kunci: Framework, Phonegap, Smartphone, Multiplatform, Rapid Application Development.

\begin{abstract}
Financial management is needed to manage finances well. Eleven reasons why financial planning needs to be done, that is because through the financial planning process we are more able to: Protect yourself and your family from the financial impact of accident risk, illness, death, and lawsuits; Reduce personal/family debt; Support finance if the age is no longer within the productive age range related to higher levels of average life expectancy in a country; Paying expenses to raise children; Providing education allocation for children to universities; Finance our daughters' marriage; To buy a vehicle; To buy a house; Be able to determine the lifestyle we want to retire; Pay the cost of long-term care costs; And inheriting the welfare to the next generation (children, grandchildren, etc.). In the current technological development of smartphone use is growing rapidly so that required smartphonebased smartphone planner app. Therefore, a smartphone-based financial planning apps was built using Phonegap framework so that the resulting application can run on a smartphone with various platforms. This system development method uses Rapid Application Development (RAD) with three phases namely, needs planning, workshop design phase, and implementation phase. Phonegap is an open source framework for building applications on mobile devices. Phonegap uses the cross-platform Application Development method so developers only create once a code base and Phonegap that transforms the application output to multiple smartphones like Android, Blackberry OS, and Windows Nurul F.R. \& Sholahuddin A.: Aplikasi...


Phone. By using the phonegap framework, the applications can be built using HTML5, CSS, Javascript, and SQLite programming languages as databases.

Keywords: Framework, Phonegap, Smartphone, Multiplatform, Rapid Aplication Development

DOI: $10.15408 /$ jti.v10i1.6818

\section{PENDAHULUAN}

Berbagai permasalahan terkait pengelolaan keuangan tidak tepat antara lain orang tua kebingungan menyekolahkan anak ke SMA, orang bunuh diri karena stres terlilit hutang, anak sekolah bekerja mencari uang untuk biaya sekolah, bayi ditinggal di rumah sakit karena orang tuanya tidak mampu membayar biaya dokter, orang menjadi gila karena warisan orang tua habis dalam sekejap, seorang ibu ketahuan mencuri di supermarket untuk membeli obat anaknya, dan banyak persoalan yang lain [5].

Kendala yang dihadapi saat ini tidak semua orang paham atau menguasai ilmu Financial Planning. Hal ini didukung hasil kuesioner yang dilakukan peneliti terhadap 50 orang pada Oktober 2014 yang tercantum pada lampiran 1. Berdasarkan data yang didapat dari responden dalam melakukan kuesioner, terdapat $80 \%$ responden yang belum melakukan perencana keuangan. Beberapa faktor yang menyebabkan responden belum dapat melakukan perencanaan keuangan yaitu, tidak memiliki tujuan keuangan yang jelas (25\%), tidak memiliki Asset/pendapatan yang cukup (20\%), terlalu banyak pengeluaran (15\%), keterbatasan pengetahuan dan informasi yang tersedia mengenai perencana keuangan (30\%), serta faktor lainnya (10\%). Selain itu, berdasarkan data yang didapat dari responden ternyata $82,4 \%$ menginginkan adanya aplikasi perencanaan keuangan berbasis smartphone.

Jawaban responden itu sangat relevan dengan kondisi saat ini mengingat pengguna smartphone berkembang pesat. Dari data yang dihimpun oleh eMarketer pada tahun 2014, pengguna smartphone di dunia saat ini adalah 1,76 milliar pengguna atau sebanyak $37.8 \%$ dari pengguna mobile di seluruh dunia. Jumlah ini meningkat sebanyak 25\% dari tahun 2013 yaitu sebanyak 1.40 miliar pengguna. Jumlah tersebut diperkirakan terus meningkat setiap tahunnya berdasarkan data yang dirilis oleh
eMarketer. Berdasarkan hal-hal tersebut penulis menyusun artikel ini yang merupakan hasil orisinil dari penelitian yang penulis lakukan.

\section{RUMUSAN MASALAH}

Bagaimana aplikasi perencana keuangan dapat dijalankan di smartphone yang mempunyai platform Android, Windows Phone, dan Blackberry10, sehingga pengguna mudah dalam akses aplikasi.

\section{PEMBAHASAN}

\subsection{Fase Perencanaan Syarat}

\subsubsection{Mencari Informasi Perencana Keuangan}

Pada tahap ini peneliti melakukan pencarian referensi berupa buku, ebook, dan jurnal mengenai perencana keuangan yang dapat dijadikan informasi pada aplikasi serta sebagai referensi perhitungan yang digunakan dalam aplikasi.

Perhitungan perencana keuangan yang digunakan dalam aplikasi yaitu Perencanaan pinjaman, Perencanaan tabungan, Perencanaan investasi, Perencanaan dana pensiun, Konsep nilai waktu uang.

\subsection{Fase Workshop Design}

Perhitungan yang digunakan dalam aplikasi perencana keuangan didasarkan pada teori yang telah dijelaskan pada bab sebelumnya. Adapun simulasi perhitungan perencanaan yang akan digunakan pada aplikasi adalah sebagai berikut:

\section{Perencanaan Pinjaman}

Perencanaan pinjaman yang digunakan pada aplikasi merupakan pinjaman yang menggunakan bunga flat. Contoh: Andi ingin meminjam dana sebesar Rp.50.000.000,selama 5 tahun. Jika bunga yang ditawarkan adalah 3\% maka berapa angsuran yang harus dibayarkan setiap bulannya?

$$
\begin{aligned}
& \text { Diketahui: } \\
& \qquad \mathrm{P}=50.000 .000
\end{aligned}
$$




$$
\begin{aligned}
& \text { B }=5 \text { tahun }(60 \text { bulan }) \\
& \begin{array}{r}
\mathrm{i}=3 \% \\
\boldsymbol{M} \boldsymbol{T}=\left(\frac{\boldsymbol{P}}{\boldsymbol{B}}\right)+
\end{array} \\
& \boldsymbol{P M T}=\left(\frac{\mathbf{5 0 . 0 0 0 . 0 0 0}}{\mathbf{6 0}}\right) \\
& +(\mathbf{5 0 . 0 0 0 . 0 0 0} \\
& \left.\times \frac{\mathbf{0}, 03}{\mathbf{1 2}}\right)
\end{aligned}
$$

\section{$P M T=958.333,33$}

Jadi jumlah angsuran per bulan yang harus dibayar sejumlah Rp.958.333,33

\section{Perencanaan Tabungan}

Contoh: Budi berencana menabung untuk liburan dengan sasaran tabungan sebesar Rp. 50.000.000,- yang akan digunakan 10 tahun lagi. Jika bunga dari tabungan tersebut adalah 5\% maka berapa dana yang harus ditabung setiap bulannya?

Diketahui:

FV (sasaran tabungan $)=50.000 .000$

$\mathrm{n}($ jangka waktu $)=10$ tahun

$\mathrm{i}($ suku bunga tabungan $)=5 \%$

$$
\begin{array}{rl}
P M T=F V & \div\left(\frac{(1+i)^{n}-1}{i}\right) \\
P M T=50.000 & .000 \\
& \div\left(\frac{\left(1+\frac{0,05}{12}\right)^{10}-1}{\frac{0,05}{12}}\right)
\end{array}
$$$$
P M T=321.994,24
$$

Jadi dana yaang harus ditabung setiap bulannya adalah Rp. 321.994,24

\section{Perencanaan Investasi}

Contoh: Budi berencana berinvestasi sebesar Rp. 500.000,- setiap bulannya selama 15 tahun pada saham yang mempunyai nilai return $15 \%$. Berapa jumlah dana yang didapatkan Budi pada saat jatuh tempo?

Diketahui:

PMT (besar investasi per bulan $)=500.000$

i (nilai return yang ditawarkan) $=15 \%$ $\mathrm{n}($ jangka waktu $)=15$ tahun

$$
F V=P M T \times\left(\frac{(1+i)^{n}-1}{i}\right)
$$

Nurul F.R. \& Sholahuddin A.: Aplikasi...

$$
\begin{aligned}
& F V=500000 \times\left(\frac{(1+0,15 / 12)^{10}-1}{0,15 / 12}\right) \\
& F V=334.253 .379,70
\end{aligned}
$$

Maka dana yang didapatkan pada saat jatuh tempo yaitu Rp.334.253.379,70

\section{Perencanaan Dana Pensiun}

Contoh: Budi saat ini berusia 25 tahun dan berencana pensiun pada saat usia 50 tahun. Saat ini Budi membutuhkan dana sebesar Rp.3.000.000,- per bulannya untuk biaya hidup. Jika usia harapan hidup diperkirakan adalah 60 tahun dan tingkat inflasi 7\% maka berapa dana yang dibutuhkan Budi saat pensiun dan berapa dana yang harus di investasikan setiap bulannya pada saham dengan nilai return $15 \%$ ?

Diketahui:

$$
\begin{aligned}
\mathrm{PV} & =3.000 .000 \\
\mathrm{i} & =7 \% \\
\mathrm{n} & =50-25=25 \text { tahun } \\
\mathrm{t} & =60-50=10 \text { tahun } \\
\boldsymbol{F V} & =\boldsymbol{P V} \times(\mathbf{1}+\boldsymbol{i})^{n} \times \mathbf{1 2} \times \boldsymbol{t} \\
\boldsymbol{F V}= & \mathbf{3 . 0 0 0 . 0 0 0} \times(\mathbf{1}+\mathbf{0 . 0 7})^{25} \times \mathbf{1 2} \\
& \times \mathbf{1 0}
\end{aligned}
$$

$F V=1.953 .875 .750,44$

Jadi total dana pensiun yang dibutuhkan adalah Rp.1.953.875.750,44. Sedangkan besar investasi yang harus dibayarkan setiap bulannya adalah sebagai berikut.

Diketahui:

$$
\begin{aligned}
& \mathrm{FV}=1.953 .875 .750,44 \\
& \mathrm{i}=15 \% / 12=0,0125 \\
& \mathrm{n}=25 \times 12=300 \\
& P M T=F V \div\left(\frac{(\mathbf{1}+\boldsymbol{i})^{\boldsymbol{n}}-\mathbf{1}}{\boldsymbol{i}}\right) \\
& \boldsymbol{P M T}=\mathbf{1 . 9 5 3 . 8 7 5 . 7 5 0 , 4 4} \\
& \quad \div\left(\frac{(\mathbf{1}+\mathbf{0 , 0 1 2 5})^{\mathbf{3 0 0}}-\mathbf{1}}{\mathbf{0 , 0 1 2 5}}\right)
\end{aligned}
$$

$P M T=602.391,83$

Maka dana yang harus diinvestasikan setiap bulannya sebesar Rp.602.391,83.

\section{Perhitungan Nilai Uang dan Waktu}

Future Value

Contoh: Tahun 2012 uang pangkal di SD Harapan Ibu sebesar Rp10.000.000 dengan tingkat inflasi pendidikan sebesar $10 \%$ per tahun, maka berapa biaya perkiraan uang pangkal nanti 10 tahun lagi atau tahun 2022?

Diketahui:

PV (nilai saat ini) $\quad=\mathrm{Rp} 10.000 .000$ $\mathrm{i}$ (tingkat inflasi) $\quad=10 \%$ 


$$
\begin{aligned}
& \text { n (jangka waktu) } \quad=10 \text { tahun } \\
& \boldsymbol{F V}=\boldsymbol{P V} \times(\mathbf{1}+\boldsymbol{i})^{\boldsymbol{n}} \\
& \mathrm{FV}=10.000 .000,-\times(1,10)^{10} \\
& \mathrm{FV}=10.000 .000,-\times(2,59374246)= \\
& 25.937 .424
\end{aligned}
$$

Jadi, 10 tahun lagi, nilai uang pangkal akan menjadi Rp 25.937.424,-

\section{Present Value}

Contoh: Tahun 2025 sebuah rumah A diperkirakan mempunyai harga Rp.2.300.000.000. Jika tingkat inflasi saat ini $7 \%$, maka harga rumah tersebut saat ini adalah?

Diketahui:

FV (nilai masa depan) $=\operatorname{Rp~2.300.000.000~}$

$\mathrm{i}$ (tingkat inflasi) $\quad=7 \%$

$\mathrm{n}$ (jangka waktu) $\quad=10$ tahun

$$
\begin{aligned}
& \boldsymbol{P V}=\boldsymbol{F V} \times\left(\frac{\mathbf{1}}{(\mathbf{1}+\boldsymbol{i})^{n}}\right) \\
& P V=2.300 .000 .000 \times\left(\frac{1}{(1,96715135)}\right) \\
& P V=1.169 .203 .376,24
\end{aligned}
$$

Jadi harga rumah tersebut saat ini adalah Rp. 1.169.203.376,24.

\section{HASIL DAN PEMBAHASAN}

Proyek yang telah selesai dibuat dapat di upload ke server Adobe Phonegap Build untuk kemudian di-compile.

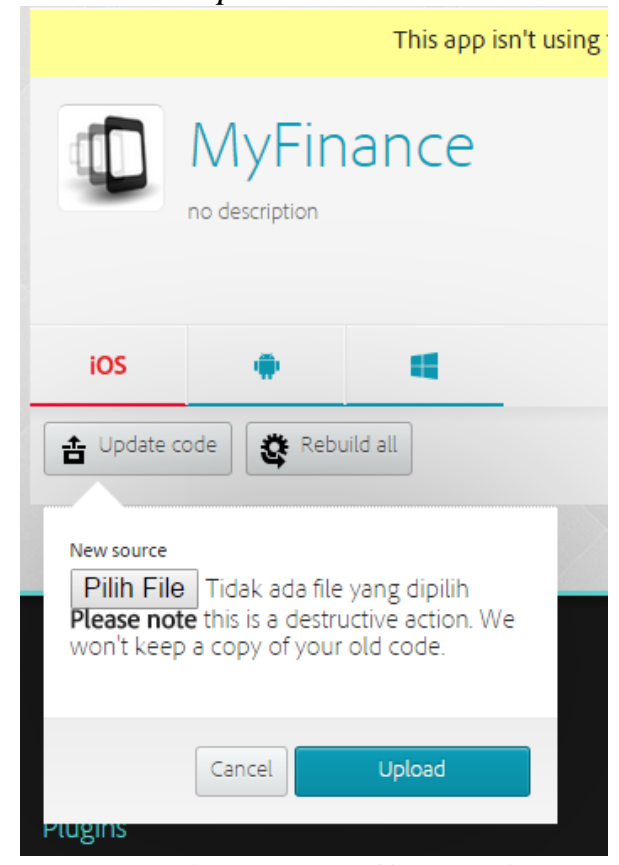

Gambar 1. Tampilan awal
Setelah project di-upload maka project selanjutnya akan di-compile secara otomatis oleh Adobe Phonegap Build dan selanjutnya akan dihasilkan beberapa file yang dapat digunakan sebagai installer pada berbagai handset seperti file berbentuk apk untuk Android dan .xap untuk windows phone. Untuk pengujian program pada handset dapat dilakukan dengan cara memindai melalui kamera pada gambar QR-code yang telah disediakan seperti gambar berikut.
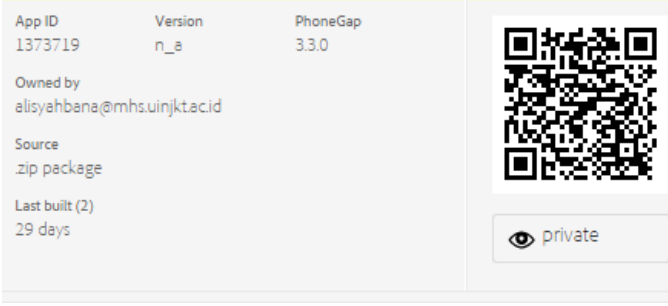

Gambar 2. QR Code

QR Code digunakan untuk instalasi aplikasi pada perangkat smartphone. Instalasi dilakukan dengan cara memindai QR Code tersebut menggunakan kamera.

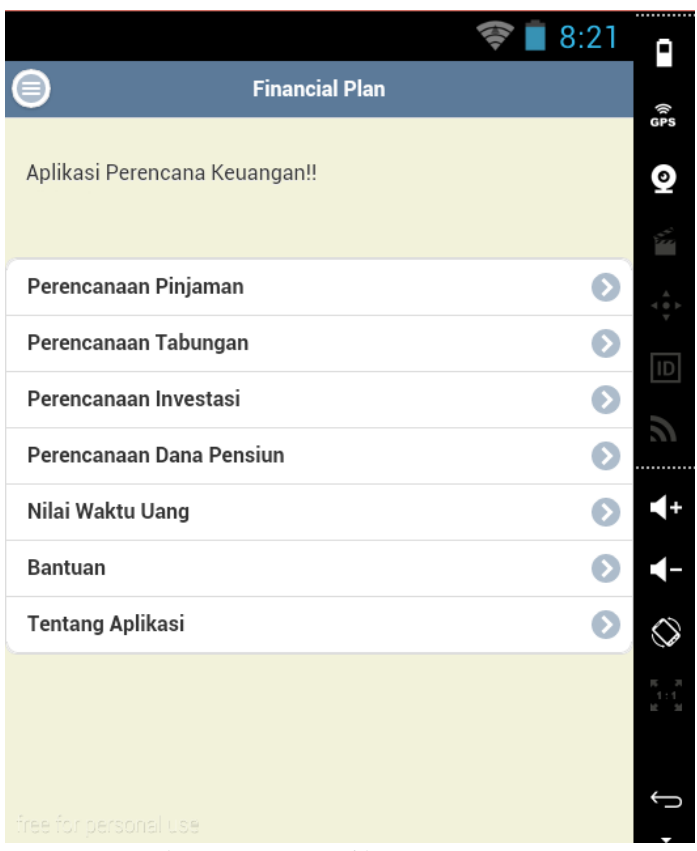

Gambar 3. Tampilan menu utama

Tampilan menu utama pada halaman awal ketika pengguna membuka aplikasi. 


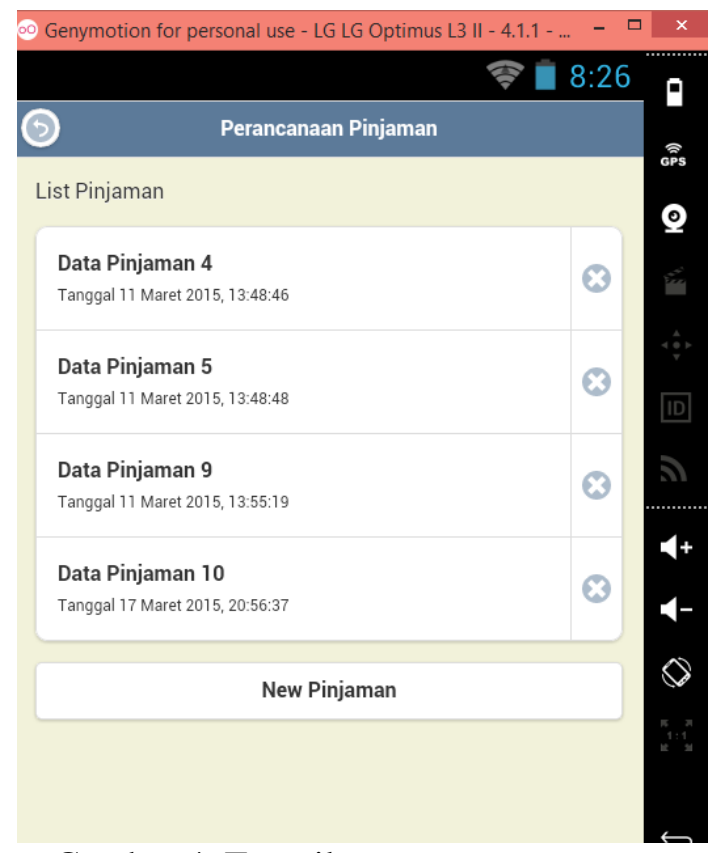

Gambar 4. Tampilan menu perencanaan pinjaman

Tampilan menu perencanaan pinjaman berisi data perencanaan pinjaman yang tersimpan atau membuat perencanaan pinjaman baru.

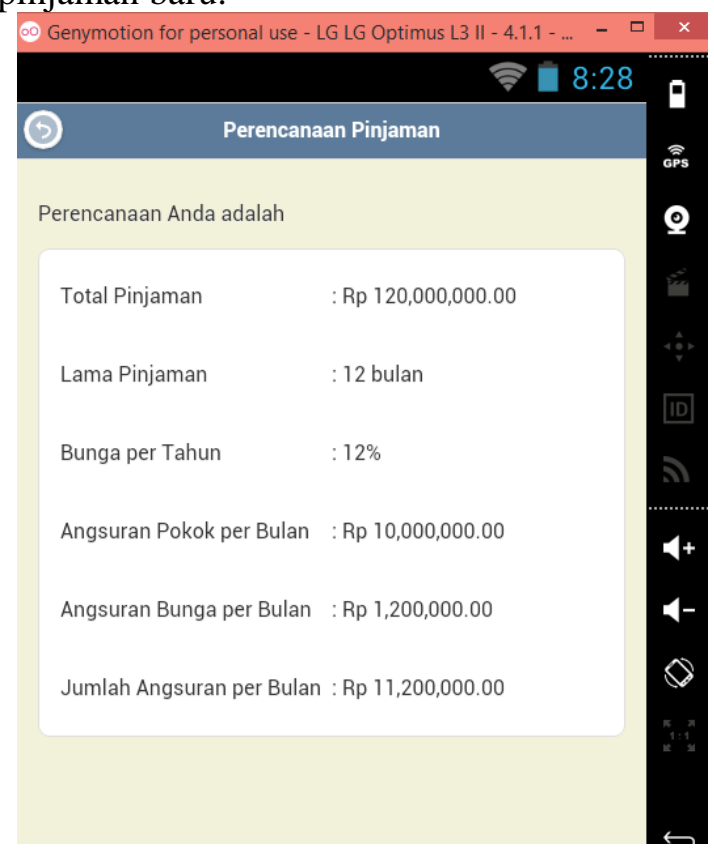

Gambar 5. Tampilan detail menu perencanaan pinjaman

Tampilan detail dari data perencanaan yang dipilih dari menu sebelumnya.

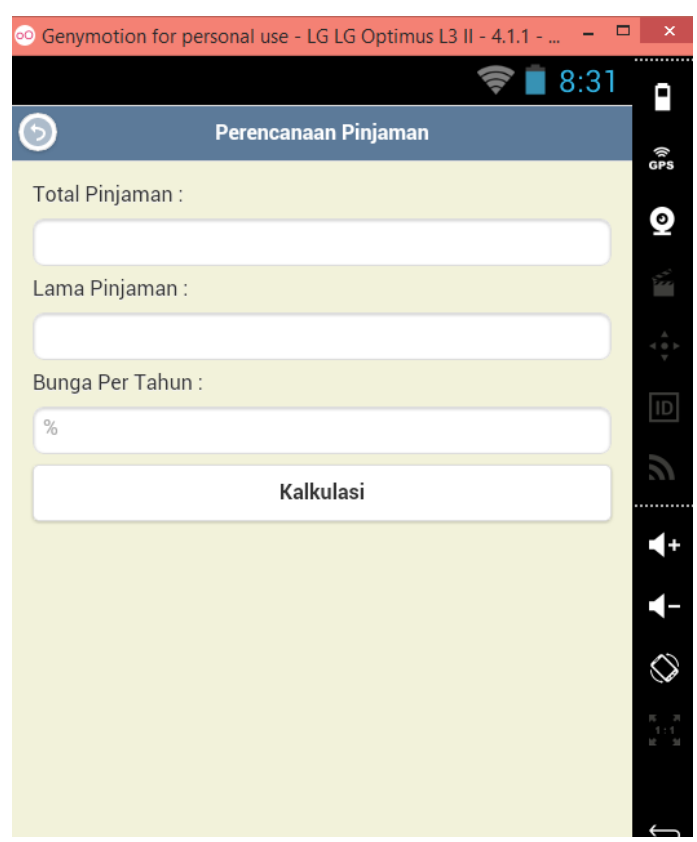

Gambar 6. Tampilan form perencanaan pinjaman

Tampilan form perencanaan pinjaman yang akan diisi oleh pengguna untuk dilakukan perhitungan.

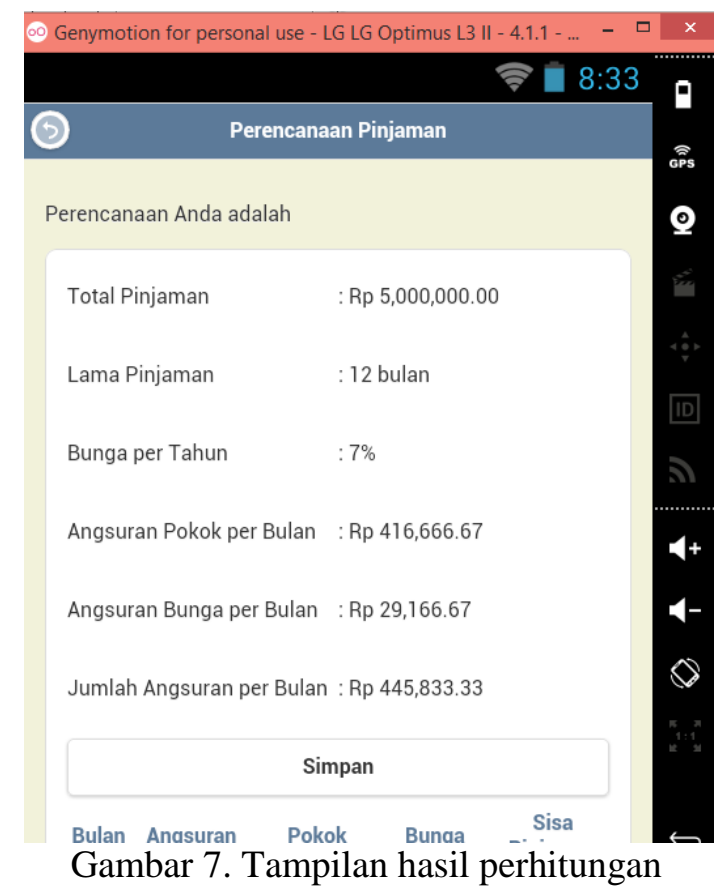

Tampilan hasil dari perhitungan perencanaan pinjaman berdasarkan data yang diinput pengguna sebelumnya. 


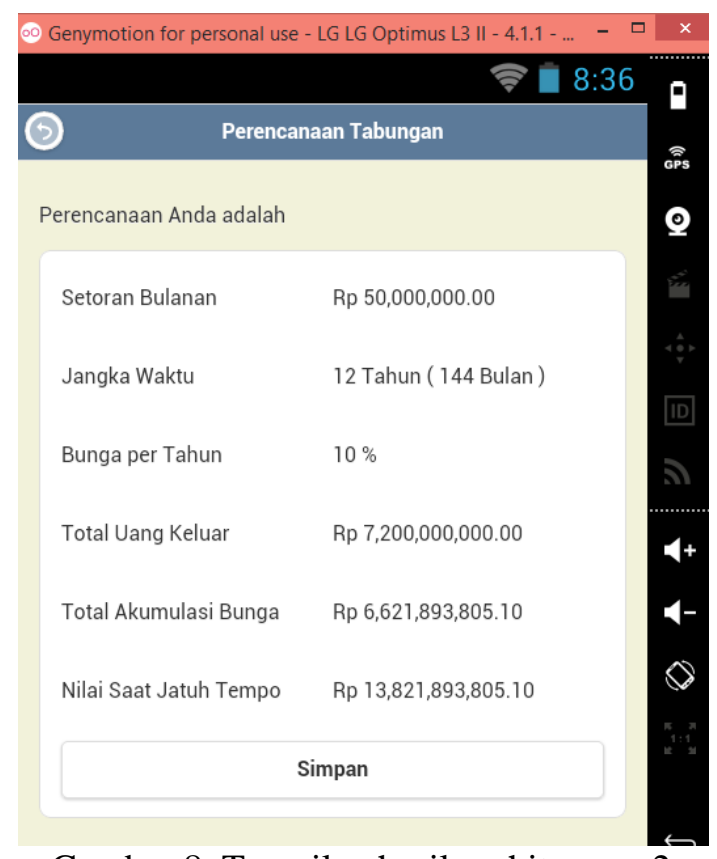

Gambar 8. Tampilan hasil perhitungan 2

Tampilan hasil dari perhitungan perencanaan tabungan berdasarkan data yang diinput oleh pengguna sebelumnya.

\section{KESIMPULAN}

Dari penelitian yang telah peneliti uraikan, maka dapat ditarik kesimpulan bahwa pengembangan aplikasi meliputi beberapa perhitungan yaitu perencanaan pinjaman, perencanaan tabungan, perencanaan investasi, perencanaan dana pensiun, dan perhitungan nilai waktu dan uang. Pengembangan aplikasi menggunakan framework Phonegap dengan tambahan jQuery mobile sebagai user interface frameworks, sehingga didapatkan aplikasi yang dapat digunakan di berbagai smartphone multiplatform, meliputi Android, Blackberry OS, dan Windows Phone. Perancangan aplikasi menggunakan Unified Modelling Language (UML) dan metode pengembangan sistem yang digunakan adalah Rapid Application Development (RAD).

\section{DAFTAR PUSTAKA}

[1] Garman and Forgue. 2011. Personal Finance. Stamford: Cengage Learning.

[2] Harsanto, Pandji. 2013. Make Your Own Plan-Perencana Keuangan. Yogyakarta: Elex Media Komputindo

[3] Hasibuan, Malayu S.P. 2009. Dasardasar Perbankan. Jakarta: Bumi Aksara.
[4] Jogianto, HM. 2005. Analisis dan Desain Sistem Informasi: Pendekatan Terstruktur Teori dan Praktek Aplikasi Bisnis. Yogyakarta: Andi.

[5] Joko, Agus. 2012. Pola Konsumsi, Investasi, dan Proteksi sebagai Indikator Perencana Keuangan Keluarga. Jakarta: Media Mahardika. 